\title{
Shifts in North Sea forage fish productivity and potential fisheries yield
}

Worsøe Clausen, Lotte; Rindorf, Anna; van Deurs, Mikael; Dickey-Collas, Mark; Hintzen, Niels T.

Published in:

Journal of Applied Ecology

Link to article, DOI:

$10.1111 / 1365-2664.13038$

Publication date:

2018

Document Version

Peer reviewed version

Link back to DTU Orbit

Citation (APA):

Worsøe Clausen, L., Rindorf, A., van Deurs, M., Dickey-Collas, M., \& Hintzen, N. T. (2018). Shifts in North Sea forage fish productivity and potential fisheries yield. Journal of Applied Ecology, 55(3), 1092-1101.

https://doi.org/10.1111/1365-2664.13038

\section{General rights}

Copyright and moral rights for the publications made accessible in the public portal are retained by the authors and/or other copyright owners and it is a condition of accessing publications that users recognise and abide by the legal requirements associated with these rights.

- Users may download and print one copy of any publication from the public portal for the purpose of private study or research.

- You may not further distribute the material or use it for any profit-making activity or commercial gain

- You may freely distribute the URL identifying the publication in the public portal 
2 TITLE: Shifts in North Sea forage fish productivity and potential fisheries yield

4 AUTHORS: Lotte Worsøe Clausen ${ }^{1,2}$, Anna Rindorf ${ }^{2}$, Mikael van Deurs ${ }^{2 *}$, Mark Dickey-

5 Collas ${ }^{1,2}$ and Niels T. Hintzen ${ }^{3}$

6

7 AUTHOR AFFILIATION:

$8 \quad{ }^{1}$ International Council for the Exploration of the Sea (ICES), H. C. Andersens Boulevard 44-

9 46, DK 1553 Copenhagen V, Denmark.

$10 \quad{ }^{2}$ National Institute for Aquatic resources, Technical University of Denmark, Kemitorvet 1,

11 DK-2800 Lyngby, Denmark.

$12{ }^{3}$ Wageningen Marine Research, PO Box 68, 1970 AB IJmuiden, The Netherlands.

13

$14 *$ Corresponding author: Mikael van Deurs, National Institute for Aquatic resources,

15 Technical University of Denmark, Kemitorvet 1, DK-2800 Lyngby, Denmark;

16 mvd@aqua.dtu.dk

17

18

19 RUNNING TITLE: Fish stock productivity and fisheries management 


\section{WORD COUNT:}

22 Total word count (excl. Suppl. Mat.): 6979

23 Summary: 344

24 Main text: 4096

25 Author contribution statement: 45

26 Acknowledgement: 88

27 References: 1784

28 Tables: 385

29 Figures: 215

30

\section{ABSTRACT:}

32 (1) Forage fish populations support large scale fisheries and are key components of marine

33 ecosystems across the world, linking secondary production to higher trophic levels. While

34 climate-induced changes in the North Sea zooplankton community are described and

35 documented in the literature, the associated bottom-up effects and consequences for fisheries

36 remain largely unidentified.

37 (2) We investigated the temporal development in forage fish productivity and the associated

38 influence on fisheries yield of herring, sprat, Norway pout, and sandeel in the North Sea. Using 
39 principal component analysis, 40 years of recruitment success and growth proxies were analysed

40 to reveal changes in productivity and patterns of synchroniety across stocks (i.e. functional

41 complementarity). The relationship between forage fish production and Calanus finmarchicus

42 (an indicator of climate change) was also analysed. A population model was used to demonstrate

43 how observed shifts in productivity affected total forage fish biomass and fisheries yield.

44 (3) The productivity of North Sea forage fish changed around 1993 from a higher average

45 productivity to lower average productivity. During the higher productivity period, stocks

46 displayed a co-variance structure indicative of functional complementarity. C. finmarchicus was

47 positively correlated to forage fish recruitment, however, for growth, the direction of the

48 response differed between species and time periods. Maximum Sustainable Yield (MSY) and the

49 associated fishing mortality $\left(\mathrm{F}_{\mathrm{msy}}\right)$ decreased by 33-68\% and 26-64\%, respectively, between the

50 higher and lower productivity periods.

51 (4) Synthesis and applications. The present results demonstrate that fisheries reference points for

52 short-lived planktivorous species are highly dynamic and respond rapidly to changes in system

53 productivity. Furthermore, from an ecosystem-based fisheries management perspective, a link

54 between functional complementarity and productivity, indicate that ecosystem resilience may

55 decline with productivity. Based on this, we advise that system productivity, perhaps monitored

56 as forage fish growth, becomes an integral part of management reference points; in both single

57 species and ecosystem contexts. However, to retain social license of biological advice when fish

58 catch opportunities are reduced, it is crucial that shifts in productivity are thoroughly

59 documented and made apparent to managers and stakeholders. 
KEY WORDS: Maximum sustainable yield; fisheries management; bottom-up effects; Portfolio effect; functional complementarity; small pelagic fisheries, forage fish, system productivity, fisheries yield; recruitment

\section{INTRODUCTION}

Changes in ecosystems are often gradual and smooth and follows for example large-scale climatological fluctuations. However, sudden rapid changes are not uncommon (Scheffer et al. 2001), and the detection of such shifts is pivotal in responsive ecosystem based management (Pikitch et al 2004; Casini et al. 2010; King et al. 2015). In the North Sea, the zooplankton community underwent considerable changes in the late 1980s and early 1990s, with the decline of the subarctic calanoid copepod Calanus finmarchicus being one of the most well documented examples (Beaugrand et al. 2003; Pitois and Fox 2006; Defriez et al. 2016). While several authors have interpreted these changes as evidence of a major system wide regime-shift (Beaugrand 2003; McQuatters-Gollop et al. 2007; Barrange et al. 2008), resulting bottom-up effects on the fish stocks are still not well understood (Reid et al. 2001, Ware and Thompson 2005).

The North Sea has a combined standing stock of commercially exploited forage fish equalling c. 7.6 million tonnes and annual yields averaging 1.5 million tonnes in the 1990s (Dickey-Collas et al. 2013; Engelhard et al. 2013). The forage fish biomass includes species such as herring (Clupea harengus), sprat (Sprattus sprattus), Norway pout (Trisopterus esmarkii), and lesser sandeel (Ammodytes marinus), which together consume c. 110 million tonnes of zooplankton 
82 annually (derived from data in Greenstreet et al. 1997; van Deurs et al. 2013a; ICES 2015a,b).

83 The combination of a central position in the food chain and large responsiveness to climate

84 change and environmental variability makes the management of forage fisheries a major

85 challenge (Smith and Jarre 2011; Fauchald et al. 2011; Fiechter et al. 2015).

86 Most North Sea fisheries are presently managed using harvest control rules targeting the fisheries

87 Maximum Sustainable Yield (MSY) (Kell et al. 2005; Mohn and Chouinard 2007). In the EU,

88 MSY is defined as the highest yield that can be taken on average from a stock under existing

89 average environmental conditions without significantly affecting reproduction (EU 2013). If all

90 forage fish stocks in the North Sea show synchronous responses to climate-driven changes in the

91 zooplankton community, this will impact the combined forage fish biomass and MSY of these

92 stocks. While scientific single-species advice on catch opportunities will likely reflect this within

93 a span of less than five years, the decreasing catch potential of the individual stocks may not be

94 as easily accepted by stakeholders (Kelly et al. 2017). On the other hand, if the responses are

95 asynchronous (i.e. inverse correlations between species), the overall biomass and yield may

96 remain relatively stable over time, providing a basis an multi-species approach to management

97 and likely enhancing acceptance among stakeholders. These stabilizing mechanisms are known

98 as the portfolio effect (Tilman 1998) or functional complementarity (Lindegren et al. 2016) and

99 have been demonstrated in several ecosystems around the world (Lluck et al. 1992; Lindegren et

100 al. 2016).

101 In the present study, we analysed time series of two productivity metrics, length anomalies and 102 recruitment success, for the major forage fish stocks in the North Sea, and tested the hypothesis 103 that overall forage fish productivity has changed alongside with the changes in the zooplankton 104 community described in the literature. Alternatively, some stocks have responded negatively and 
105 106 107

108 109

others positively (i.e. functional complementarity). Lastly, we simulated stock development to demonstrate implications for MSY and the potential forage fish biomass in the North Sea.

\section{MATERIALS AND METHODS}

\section{Metrics of fish productivity}

The analyses combined data from five major forage fish stocks in the North Sea: herring, Norway pout, sprat, northern sandeel, and southern sandeel (the southern and northern sandeel stock correspond to stock assessment area 1 and 3, respectively; see ICES 2015b). Growth and recruitment success were used as metrics of fish productivity (Kell et al. 2016). A pre-analysis revealed that annual growth effects exceeded cohort effects. Hence, growth was derived from average annual length anomalies of consistently sampled ages, rather than as cohort specific estimates. Length at age data for herring, sprat and Norway pout were derived from the ICES International Bottom Trawl Survey Database (February 1967 to 2014). The surveys contributing to this database use demersal trawls to sample the abundance of fish. The survey catch rates are used in both herring, sprat and Norway pout stock assessments in the area, and for herring and sprat, the results from this survey shows high consistency with data from acoustic surveys when used to estimate abundance indices. In contrast to e.g. acoustic surveys, the sampling does not target aggregations of fish and hence avoids possible bias if high aggregations tend to contain e.g. smaller individuals. Total catch and length composition of the majority of species is recorded in each haul. Haul duration generally varies between 15 and 35 minutes, and on average two trawl hauls are conducted within each $\sim 30 \times 30 \mathrm{~nm}$ statistical rectangle in a grid covering the 
127 entire North Sea, though not all rectangles were monitored prior to the 1980s. The length of the

128 time series differed between the three stocks as sprat and Norway pout were not aged up until

1291976 and 1984, respectively.

130 Age-length keys were estimated using continuation-ratio logits (Rindorf and Lewy 2001;

131 Gerritsen et al. 2006; Rindorf et al. 2008). All fish ages were measured in years from January 1

132 in the year of spawning. The mean length of each stock $s$ at age $a$ in year $y,\left(l_{a, y, s}\right)$, was

133 calculated by estimating average length of all fish caught in a given age group. Unfortunately,

134 the data are often recorded in plus-groups for older ages and hence, age segregated data for older 135 ages are not consistently reported.

136 Sandeel are not representatively caught in the trawl surveys, and therefore length at age data for

137 sandeel were derived from fish sampled from the commercial fishery in the second quarter,

138 which roughly captures the fishing season. The samples are a combination of on-board samples

139 (samples organized by control agencies) and port samples. Sample size is approximately one $\mathrm{kg}$

140 taken randomly from the catch. Mean length at age in each statistical rectangle was estimated by

141 combining sampled length distributions with age-length keys. Length at age in a given year was

142 estimated as the average mean length in the commercial catches. Samples were available from

1431978 to 2014 for the southern sandeel stock (except from 1990) and from 1982 to 2014 for the

144 northern stock. These procedures provided yearly estimates of mean length at age of northern

145 and southern sandeel, sprat and Norway pout of ages 2 to 4 and herring of ages 2 to 5 . Fish of

146 age 0 and 1 were not included as these were only partially recruited to the survey sampling gear.

147 The estimated mean lengths at age were then used to estimate the annual mean length anomalies.

148 Length at ages 2+ was highly correlated between ages within years for all stocks (Pearson's

149 product moment correlation: coefficients $>0.60, \mathrm{p}<0.001$ for all ages and stocks). This 
150 indicates that a common factor is influencing the length of all ages in a given year. Reducing

151 complexity of data by computing the anomalies was therefore desirable. The mean length

152 anomaly of fish, $\lambda_{y, s}$, was computed as:

$153 \quad \lambda_{y, s}=\left(\frac{l_{2, y, s}-\bar{l}_{2, s}}{\bar{l}_{2, S}}+\frac{l_{3, y, s}-\bar{l}_{3, s}}{\bar{l}_{3, s}}+\cdots+\frac{l_{\max , y, s}-\bar{l}_{\max , s}}{\bar{l}_{\max , s}}\right) /(\max -1)$,

154 where $l_{a, y, s}$ is the length at age $a$ in year $y$ of stock $s, \bar{l}_{a, s}$ is the average length at age $a$ of stock $s$ 155 across all years and $\max$ denotes the oldest age included in the analysis for stock $s$ ( $\max$ is 5 for 156 herring and 4 for other stocks; max - 1 is used in the denominator, since age 1 fish is not included 157 in the analysis, as explained above).

158 Data on recruitment $(R)$ and spawning stock biomass $(S)$ were derived from stock assessments 159 (ICES 2015a,b). Recruitment success was estimated as $\ln (R / S)$ and the annual anomaly of all160 time series was estimated as described for length at age. However, to avoid erroneous 161 conclusion, the type of analysis was repeated with residuals from a Ricker relationship (see 162 online supporting information).

\section{Statistical analysis of data time series}

165 Data were analysed both within each stock and across stocks. Analyses carried out within each 166 stock served to identify time trends in length anomaly and recruitment success, and was 167 conducted using Pearson's product moment correlation tests. The across stock analyses focused 168 on the more general correlation structure and was conducted using principle components 169 analyses (PCA) in line with the approach described in Lindegren et al. (2016). 
170 Initial spectral analyses showed periodicities in data. Data were therefore also analysed as three

171 year running averages to differentiate between correlation patterns resulting from multi-annual

172 trends and correlation patterns resulting from year-to-year fluctuations. Applying running

173 averages, rather than the underlying annual values, can potentially introduce an artificial

174 autocorrelation in the data reducing the effective number of degrees of freedom below the

175 number of observations. To remove this source of bias the degrees of freedom was reduced in

176 tests in accordance with the method described in Pyper and Peterman (1999).

177 As PCA estimates a common correlation structure throughout the data set, we analysed whether

178 there were significant changes in the correlation structure over time. The analysis was used to

179 identify the most likely single year breakpoint in the time series (across stocks). The breakpoint 180 analysis was performed by estimating the parameters in the following model:

$182 \mathrm{X}[\mathrm{t}] \sim \mathrm{N}\left(\mathrm{Z}[\mathrm{t}], \mathrm{I} \times \mathrm{s}^{2}\right)$

184 Where the observation at time $\mathrm{t}$ is $\mathrm{X}[\mathrm{t}]=(\mathrm{x}[\mathrm{t} 1], \ldots, \mathrm{x}[\mathrm{t} 5])$, with $\mathrm{x}[\mathrm{t} 1]$ being the observed 185 productivity value for stock 1 at time $t$ and so forth. $Z[t]=(z[t 1], \ldots, z[t 5])$ denotes the underlying 186 process describing productivity and I is a matrix with 1 in the diagonal and 0 elsewhere, and $\mathrm{s}^{2}$ is

187 the variance parameter. The underlying process model for $\mathrm{Z}$ is assumed to be a multivariate 188 random walk with a common correlation parameter $\rho_{1}$ for all pairs up to time $\tau$ after which point 189 the common correlation parameter is $\rho_{2}$. The log likelihood of each possible breakpoint $\tau$ is then 190 evaluated to determine if there is a clear change point in the correlation structure.

191 Lastly, a PCA analysis for each productivity metric was conducted. Based on the results from the 192 breakpoint analysis described above, the PCA for length anomalies was split into the period 
193 before and including 1993 and the period after 1993. The contribution of the different stocks to 194 the first and second principal component (PC1 and PC2, respectively) and the time trends of PC1 195 and PC2 were examined.

\section{Zooplankton}

198 To investigate if trends in forage fish productivity were correlated to changes in the zooplankton, 199 the PC1 from all three PCAs was related to an annual Calanus finmarchicus North Sea index 200 using Pearson's product moment correlation tests. C. finmarchicus abundance (numbers $\mathrm{m}^{-3}$ ) was 201 derived from the continuous plankton recorder survey (CPR, Batten et al. 2003; Reid et al. 2003) 202 and provided by the Sir Alister Hardy Foundation for Ocean Science, SAHFOS (Richardson et 203 al. 2006; Stevens and Johns 2017), where it was delivered in the CPR standard format of 204 monthly values for each of the four CPR standard areas within the North Sea (c1, c2, d1, and d2).

205 The annual index was subsequently calculated by first deriving the median value across all 206 months and then the median across all areas.

209 In order to demonstrate how changes in recruitment and growth impact MSY, the associated mortality $\mathrm{F}_{\mathrm{msy}}$ and the potential forage fish spawning stock biomass (i.e. spawning stock biomass

211 at a fishing mortality of zero), we simulated stock dynamics for the period before and after 1993

212 (see estimation of time series breakpoints above). Calculations were based on a dual simulation 213 model where the yield resulting from a given fishing mortality is determined based on a 214 'perceived stock' and subsequently removed from a 'true' stock, which receives a stochastic 
215 annual recruitment. The model framework is in accordance with the models described in

216 Butterworth and Punt (1999) and Butterworth (2007) and ICES (2013). Fmsy is defined as the

217 fishing mortality resulting in the highest long-term average yield that can be obtained while at

218 the same time ensuring that probability of the spawning stock $(S)$ falling below the lower limit

219 biomass reference point, represented by $B_{\text {lim }}$, does not exceed 5\% (ICES 2014). Simulations of

220 stocks development when managed according to $F_{m s y}$ were carried out for a period of twenty

221 years and repeated 1000 times. The probability of achieving a spawning stock below $\mathrm{B}_{\text {lim }}$

222 (adopted from the ICES reports (ICES 2015a,b)) was calculated as the number of simulated

223 years with $S<\mathrm{B}_{\text {lim }}$ divided by the total number of simulated years. To demonstrate the effects of

224 reduced productivity on the potential combined forage fish biomass, we also simulated the

225 potential combined forage fish spawning stock before and after 1993 in a no-fishing scenario

$226(\mathrm{~F}=0)$. Simulations were carried out for each stock for the two periods identified in the

227 breakpoint analysis described above (1983-1993 and 1994-2013). Period-specific stock-

228 recruitment relationships and mean weight at age were calculated from values in the ICES

229 reports for the respective stocks ( ICES 2015a,b). For simplicity, we applied stock-recruitment

230 relationships of the hockey-stick type (Barrowman and Myers 2000) with time invariant

231 breakpoints at $\mathrm{B}_{\text {lim. }}$. Hence, only the upper level of the hockey stick and mean weight at age

232 varied between the two periods (before and after 1993). As a simplification and to avoid making

233 prejudiced assumptions, correlations between stocks were not accounted for. Hence, the focus of

234 the simulations were merely to establish the overall change between the two periods defined

235 above. A more detailed description of the model and input data can be found in the online

236 supporting information. 


\section{RESULTS}

\section{Time trends in productivity within stocks}

241 All stocks displayed decreasing trends in production, reflected in either length anomalies,

242 recruitment success or both. Length anomalies showed a significant declining trend in four out of 243 five stocks, sprat being the exception (Table 1, Fig. 1). Using 3-year running averages, 244 significant trends were detected for herring and northern sandeel, although all stocks but 245 southern sandeel showed a tendency toward lower recruitment success late in the time series 246 (Table 1, Fig. 2). Overall these results demonstrate a shift from a period of high forage fish 247 productivity (across all species and stocks) to a period of considerably lower productivity.

249 Co-variation patterns in productivity across stocks

250 The across stock co-variation structure in the length anomaly data changed significantly over 251 time, with the most likely breakpoint being in 1993. In contrast, the co-variation structure of 252 recruitment success remained the same throughout the time series. The first principal component 253 (PC1) for length anomaly up to 1993 explained most of the variation (PC1: 80\%, PC2: 11\%) 254 (Table 2), hence, the across stock correlation structure was strong. Up till 1993 PC1 was 255 positively correlated to length anomaly of sprat and the two sandeel stocks and negatively 256 correlated to herring and Norway pout.

257 After 1993, the across stock correlation structure in the length anomaly data was weaker, as 258 indicated by the relatively low proportion of variation explained by PC1 (PC1: 37\%, PC2: 31\%) 259 (Table 2). PC1 was now negatively correlated to length anomaly of sprat and the northern 
sandeel stock but positively correlated to herring, Norway pout and the southern sandeel stock.

261 Hence, a high value of PC1 prior to 1993 corresponds to high growth of sprat and sandeel of

262 both stocks and a low growth of herring and Norway pout whereas a high value of PC1 after

2631993 corresponds to low growth of sprat and northern sandeel and a high growth of herring,

264 Norway pout and southern sandeel. To make the results from the two periods more intuitively

265 comparable, we used PC1 in analyses of the period before 1993. Using this method, a high value

266 of PC1 corresponds to a high growth of herring and Norway pout and a low growth of sprat and

267 northern sandeel in both periods.

268 PC1 for recruitment success explained $42 \%$ of the total variation and PC2 added another $33 \%$.

269 PC1 was positively correlated to the recruitment success of all stocks, although the correlation

270 with southern sandeel was weak (Table 2). PC2 was positively correlated to southern sandeel and

271 negatively correlated to sprat, indicating that years of high recruitment success for one of these

272 stocks matched up with years of poor recruitment success for the other. PC1 showed an overall

273 significant decreasing trend over time (Pearson's product moment correlation: correlation -0.76 ,

$274 \mathrm{p}=0.002$ ), indicating a general decrease in forage fish recruitment success. For further

275 information about correlations between individual stocks can be found in Table S3 in online 276 supporting information.

\section{Zooplankton}

279 The annual $C$. finmarchicus index was positively correlated to $\mathrm{PC} 1$ for recruitment $(\mathrm{c}=0.41, \mathrm{t}=$ $2802.32, \mathrm{df}=26, \mathrm{p}=0.029), \mathrm{PC} 1$ for growth (i.e. length anomalies) in the late period (after 1993) (c

$281=0.51, \mathrm{t}=2.54, \mathrm{df}=18, \mathrm{p}=0.021)$, and PC1 for growth in the early period (up till 1993) $(\mathrm{c}=$ $0.59, \mathrm{t}=-2.52, \mathrm{df}=12, \mathrm{p}=0.027$ ) (Fig. 3). Hence, a higher density of $C$. finmarchicus was 
283 consistent with higher growth of herring and Norway pout and lower growth of sprat and

284 northern sandeel in both periods.

\section{Productivity and maximum sustainable yield}

287 Weight at age in the catch decreased by $13 \%$ on average across age classes and stocks between

288 the early period and the late period (before and after 1993), and mean recruitment dropped nearly

$28930 \%$ on average (Table 3). These reductions led to a decrease in MSY and F FS of around $47 \%$

290 and 46\%, respectively (ranging from 26 to 69\%, Table 3). In comparison the reduction in the

291 potential forage fish spawning stock biomass (given a fishing mortality of zero) amounted to c.

$29225 \%$ (Fig. 4). The greater decrease in MSY is caused by the necessity to sustain the stock above

293 the unchanged biomass limit reference point $\mathrm{B}_{\text {lim. }}$.

\section{DISCUSSION}

296 Our results revealed that a shift in North Sea forage fish productivity (reflected in recruitment to

297 the stocks or the growth of individuals) occurred in succession with the well documented shifts

298 in the plankton community (Pitois and Fox 2006; McQuatters-Gollop et al. 2007). The year of

2991993 represented the statistically most likely single-year breakpoint between a period of higher

300 correlation in forage fish productivity and a subsequent lower correlation.

301 The shift in productivity around 1993 was consistent across stocks. Hence, the functional

302 complementarity hypothesis was not supported over the entire time period. However, in the

303 period before 1993, productivity (represented by growth) was inversely correlated between two

304 different subsets of forage fish stocks (sprat and sandeel vs. herring and Norway pout), indicating 
that functional complementarity may have existed when productivity was high. Different species within the same functional group, respond in different ways to environmental drivers (Chavez et al. 2003; Lindegren et al. 2016). The stocks experience different prey fields, prefer different prey (Last 1987; Albert 1994; Raab et al. 2012; van Deurs et al. 2013b), and may be expected to display different responses to changes in food availability (Defriez et al. 2006). Prior to 1993, years favouring growth of herring and Norway pout were different from those favouring sandeel and sprat, creating a synchrony among some segments of the forage fish community and an asynchrony among others. Thus in periods with high forage fish productivity, the different spatial distributions and life histories may result in divergent growth patterns, facilitating overall stability in the forage fish community (i.e. functional complementarity). However, below a certain threshold, the functional complementarity was no longer be sustained (i.e. after 1993).

The simulated population dynamics revealed that the reduction in forage fish productivity around 1993 roughly halved the maximum sustainable yield (MSY) and $F_{m s y}$ (the fishing mortality associated with MSY) and reduced the potential forage fish spawning stock biomass by c. $25 \%$. This drop in productivity is comparable to a study conducted on North Sea cod (Kell et al. 2016). However, Shephard et al. (2014) found that the forage fish biomass in the North Sea has remained relatively stable between 1983 and 2012, it may therefore be so that productivity changes amongst the forage fish stocks after all have been successfully counteracted by appropriate management action (Dickey-Collas et al. 2014). Recruitment and spawning stock is often poorly correlated (Szuwalski et al. 2015; Kell et al. 2016). Hence, we chose to use a simple hockey stick relationship for the simulations, rather than making assumptions about more complicated relationships (Chen and Irvine 2001). Another simplification made here was that 
327 reference points were kept constant across the period of change, as opposed to having dynamic

328 reference points (Punt et al. 2013).

329 Our analysis suggested a positive relationship between C. finmarchicus and forage fish

330 recruitment. The importance of $C$. finmarcicus eggs and nauplii as food for fish larvae has been

331 highlighted in relation to sandeel and cod (Arnott and Ruxton 2002; Beaugrand et al. 2003, van

332 Deurs et al. 2009). For sprat and Norway pout, recruitment success has not formerly been linked

333 to C. finmarchicus. However, sprat recruitment is reportedly positively correlated to temperature

334 (Baumann et al. 2006). Hence, variation in temperature in the southern North Sea could

335 potentially explain the inverse patterns in recruitment success of sandeel in the southern area and

336 sprat. The substantial downward shift in key elements of the plankton (Pitois and Fox 2006;

337 McQuatters-Gollop et al. 2007) and stock production across a range of zooplanktivorous species

338 (results presented here), seem to indicate a declining primary production (Ware et al. 2005).

339 However, other studies point to changes in zooplankton species composition as the cause of

340 reduced fish growth (Beaugrand et al. 2003; van Deurs et al. 2015). Factors such as spawning

341 site diversity or the frequency of unlikely events governing extreme recruitment outburst (Pepin

342 2015; Lowerre-Barbieri et al. 2016) have also been proposed as drivers of variation in fish stock

343 production. However, such mechanisms would not be expected to influence growth as found in

344 the present study.

345 With the growing interest in implementing ecosystem based fisheries management (Pikitch et al.

346 2004), the regime-shift subject is gradually becoming an integral part of the scientific endeavors

347 in fisheries biology and management (Anderson and Piatt 1999; Barange et al. 2008, King et al.

348 2014). Several studies have argued that the North Sea underwent a major regime-shift in the late

349 1980s, manifested first as changes in primary and secondary production (Reid et al. 2001; 
McQuatters-Gollop et al. 2007). This is just a few years earlier than the break point identified in the present study and therefore credible that the shift in forage fish production is the consequence of such a regime-shift. However, based on the time series length presented here and the large inter-annual fluctuations in weight-at-age and recruitment, that even after converting to three years running averages were still distinctive for some stocks, it cannot be concluded if an abrupt regime-shift like transition from one state to another has truly taken place, or if the change we observed reflects climatic oscillations on a multi-decadal time-scale, as reported for anchovysardine systems (Chavez et al. 2003). Such differentiation may, however, be worth pursuing in the future, as it would be a major asset in models of resource fluctuations and execution of ecosystem based management actions (King et al. 2014).

Here we have shown that what appears to have been climate induced changes in productivity in the North Sea had substantial effects on MSY and $\mathrm{F}_{\mathrm{msy}}$. While, similar findings have previously been presented for cod, this is the first study to show how productivity in an entire forage fish community can shift in less than a decade, reducing the sustainable catches opportunities by a factor of two across all major forage fish stocks (Kell et al. 2005; Mohn and Chouinard 2007; Morgan et al. 2014). In addition, this study reveals a link between productivity and functional complementarity among stocks (the portfolio effect), supporting one of the recommendations put forward in Dickey-Collas et al. (2014), that a forage fish community cannot be managed as an overall resilient pool of biomass where one species take over the niche when another is in decline. Hence, we advocate against having a long-term maximum on the total removal of forage fish (i.e. a community MSY), which is in contrast to what has been suggested for some other systems (e.g. Lluck et al. 1992). At least, system productivity ought to be integrated into any long-term management plan and fisheries reference points should be kept dynamic, irrespective 
373 of whether it is made in a single species or multi species context. Furthermore, it is here

374 demonstrated how already existing time series of forage fish growth and reproductive output can

375 potentially be used as indicators of system productivity, and last but not least, to ensure social

376 license, when catch opportunities are reduced as a result of declining productivity,

377 documentation and communication to stakeholders is critical (Kelly et al. 2017).

\section{ACKNOWLEDGEMENTS}

381 This study received funding from (1) the European Community’s Seventh Framework

382 Programme (FP7/2007-2013) under grant agreement MYFISH number 289257 (AR, LWC,

$383 \mathrm{NH})$, (2) COFASP ERA-NET project, which has received funding from the European Union's

384 Seventh Framework Programme for research, technological development and demonstration

385 under grant agreement no. 321553 (GOFORIT project), and by the national funding agency of

386 Denmark (Innovationsfonden) (MVD), (3) the Danish council of independent research DFF-

387 4002-00114 (MVD), and (4) the European Fisheries and Maritime Fund (33113-B-15-002,

388 Minestry of Environment and Food in Denmark) (MVD, LWC).

\section{Authors' contributions}

391 Author Contributions statement: - All authors were involved in conceiving the ideas and 392 designing methodology; AR and MVD collected and analysed the data; LWC, AR and MVD led 393 the writing of the manuscript. All authors contributed critically to the drafts and gave final 394 approval for publication. 
396 Data accessibility

397 Data are available in the Dryad Digital Repository doi:10.5061/dryad.tq1f7

399 REFERENCES

400

401 Anderson, P.J., and Piatt, J.F. (1999) Community reorganization in the Gulf of Alaska following 402 ocean climate regime shift. Marine Ecology Progress Series, 117-123

403 Albert, O.T. (1994) Biology and ecology of Norway pout (Trisopterus esmarki Nilsson, 1855) in 404 the Norwegian Deep. ICES Journal of Marine Science 51, 45-61

405 Arnott, S.A. and Ruxton, G.D. (2002). Sandeel recruitment in the North Sea: demographic, 406 climatic and trophic effects. Marine Ecology Progress Series 238, 199-210

407 Batten, S.D., Clarke, R., Flinkman, J., Hays, G., John, E., John, A.W.G., Jonas, T.D., Lindley, 408 J.A., Stevens, D. and Walne, A. (2003) CPR sampling: the technical background, materials and 409 methods, and issues of consistency and comparability. Progress in Oceanography 58,193-215

410 Baumann, H., Hinrichsen, H.H, Möllmann, C., Köster, F.W., Malzahn, A.M. and Temming., A. 411 (2006) Recruitment variability in Baltic Sea sprat (Sprattus sprattus) is thightly coupled to 412 temperature and transport patterns affecting the larval and early juvenile stages. Can J Fish 413 Aquat Sci. 63, 2191-2201 
414 Barange, M., Beaugrand, G., Harris, R., Perry, R.I., Scheffer, M., and Werner, F. (2008) Regime

415 shifts in marine ecosystems: detection, prediction and management. Trends in Ecology \&

416 Evolution 23(7), 402-409

417 Beaugrand G., Brander K.M., Lindley J.A., Souissi S. and Reid P.C. (2003) Plankton effect on

418 cod recruitment in the North Sea. Nature 426, 661-664

419 Barrowman, N.J. and Myers, R.A. (2000) Still more spawner-recruitment curves: the hockey 420 stick and its generalizations. Canadian Journal of Fisheries and Aquatic Sciences, 57, 665-676

421 Butterworth, D.S. (2007) Why a management procedure approach? Some positives and 422 negatives. ICES Journal of Marine Science 64, 613-617

423 Butterworth, D.S. and Punt, A.E. (1999) Experiences in the evaluation and implementation of 424 management procedures. ICES Journal of Marine Science 56, 985-998

425 Casini, M., Bartolino, V., Molinero, J.C. and Kornilovs, G. (2010) Linking fisheries, trophic 426 interactions and climate: threshold dynamics drive herring Clupea harengus growth in the central 427 Baltic Sea. Marine Ecology Progress Series 413, 241-252

428 Chavez, F.P., Ryan, J., Lluch-Cota, S.E. and Niquen, M. (2003) From anchovies to sardines and 429 back: multidecadal change in the Pacific Ocean. Science 299, 217-221

430 Chen, D.G. and Irvine, J.R. (2001) A semiparametric model to examine stock recruitment 431 relationships incorporating environmental data. Canadian Journal of Fisheries and Aquatic

432 Sciences 58, 1178-1186 
433 Defriez, E.J. Sheppard, L.W., Reid, P.C. and Reuman, D.C. (2016) Climate change-related 434 regime shifts have altered spatial synchrony of plankton dynamics in the North Sea. Global 435 Change Biology 22, 2069-2080

436 Dickey-Collas, M., Engelhard, G.H., Rindorf, A., Raab, K., Smout, S., Aarts, G., van Deurs, M., 437 Brunel, T., Hoff, A., Lauerburg, R., Garthe, S., Andersen, K.H, Scott, F., van Kooten, T., Beare, 438 D. and Peck, M.A. (2014) Ecosystem-based management objectives for the North Sea: riding the 439 forage fish rollercoaster. ICES Journal of Marine Science 71, 128-142

440 Engelhard, G.H., Peck, M.A., Rindorf, A., Smout, S.C., van Deurs, M., Raab, K., Andersen, K. 441 H., Garthe, S., Lauerburg, R. A. M., Scott, F., Brunel, T., Aarts, G., van Kooten, T. and Dickey442 Collas, M. (2013) Forage fish, their fisheries, and their predators: who drives whom? ICES 443 Journal of Marine Science 71, 90-104

444 EU (2013) Regulation (EU) No 1380/2013 of the European Parliament and of the Council of 11 445 December 2013 on the Common Fisheries Policy, Amending Council Regulations (EC) No 446 1954/2003 and (EC) No 1224/2009 and Repealing Council Regulations (EC) No 2371/2002 and 447 (EC) No 639/2004 and Council Decision 2004/585/EC Official Journal of the European Union, 448 Brussels.

449 Fauchald, P., Skov, H., Skern-Mauritzen, M., Johns, D., and Tveraa, T. (2011). Wasp-waist 450 interactions in the North Sea ecosystem. PLoS One, 6(7), e22729

451 Fiechter, J., Rose, K.A., Curchitser, E.N. and Hedstrom, K.S. (2015) The role of environmental 452 controls in determining sardine and anchovy population cycles in the California Current:

453 Analysis of an end-to-end model. Progress in Oceanography 138, 381-398 
454 Gerritsen, H.D., McGrath, D. and Lordan, C. (2006) A simple method for comparing age-length 455 keys reveals significant regional differences within a single stock of haddock (Melanogrammus 456 aeglefinus). ICES Journal of Marine Science 63, 1096-1100

457 Greenstreet S.P.R., Bryant A.D., Broekhuizen N., Hall S.J. and Heath M.R. (1997) Seasonal 458 variation in the consumption of food by fish in the North Sea and implications for food web 459 dynamics. ICES Journal of Marine Science 54, 243-266

460 ICES (2013) Report of the Workshop on Guidelines for Management Strategy Evaluations. ICES 461 CM 2013/ACOM:39. Available from the International Council for the Exploration of the Sea, 462 Copenhagen.

463 ICES (2014) Report of the Workshop to consider reference points for all stocks

464 (WKMSYREF2). ICES CM 2014/ACOM:47. Available from the International Council for the 465 Exploration of the Sea, Copenhagen.

466 ICES (2015a) Report of the Working Group for the Assessment of Demersal Stocks in the North 467 Sea and Skagerrak (WGNSSK). ICES CM 2015/ACOM:13. Available from the International 468 Council for the Exploration of the Sea, Copenhagen.

469 ICES (2015b) Report of the Herring Assessment Working Group for the Area South of $62^{\circ} \mathrm{N}$ 470 (HAWG). ICES CM 2015/ACOM:03. Available from the International Council for the 471 Exploration of the Sea, Copenhagen.

472 Kell, L.T., Pilling, G.M. and O'Brien, C.M. (2005) Implications of climate change for the 473 management of North Sea cod (Gadus morhua). ICES Journal of Marine Science 62, 1483-1491 
474 Kell, L.T., Nash, R.D.M., Dickey-Collas, M., Mosqueira, I., Szuwalski, C. (2016). Is Spawning

475 Stock Biomass A Robust Proxy for Reproductive Potential? Fish and Fisheries 17, 596-616

476 Kelly, R., Pecla, G. T. and Fleming, A. (2017) Social licence in the marine sector: A review of

477 understanding and application. Marine Policy 81, 21-28

478 King, J.R., McFarlane, G.A., and Punt, A.E. (2015) Shifts in fisheries management: adapting to

479 regime shifts. Philosophical Transactions of the Royal Society of London B: Biological Sciences, $480 \quad 370(1659), 20130277$

481 Last, J. M. (1987) The food of immature sprat (Sprattus sprattus (L.)) and herring (Clupea

482 harengus L.) in coastal waters of the North Sea. ICES Journal of Marine Science 44, 73-79

483 Lluck, D., Schwartlose, R.A., Serra, R., Parrish, R., Kawasaki, T., Hedgecock, D. and Crawford, 484 R. J.M. (1992) Sardine and anchovy regime fluctuations of abundance in four regions of the 485 world oceans: a workshop report. Fisheries Oceanogr 1, 339-347

486 Lindegren, M., Checkley, D.M., Ohman, M.D., Koslow, J.A. andGoericke, R. (2016) Resilience 487 and stability of a pelagic marine ecosystem. Proc R Soc B 283, 20151931

488 Lowerre-Barbieri, S., DeCelles, G., Pepin, P., Catalán, I.A., Muhling, B., Erisman, B., ... and 489 Tringali, M.D. (2016) Reproductive resilience: a paradigm shift in understanding spawner-recruit 490 systems in exploited marine fish. Fish and Fisheries 18(2), 285-312

491 McQuatters-Gollop, A., Raitsos, D.E., Edwards, M., Pradhan, Y., Mee, L.D., Lavender, S.J. and 492 Attrill, M.J. (2007) A long-term chlorophyll dataset reveals regime shift in North Sea 493 phytoplankton biomass unconnected to nutrient levels. Limnology and Oceanography 52, 635$494 \quad 648$ 
495 Mohn, R.K. and Chouinard, G.A. (2007) Harvest control rules for stocks displaying dynamic

496 production regimes. ICES Journal of Marine Science 64, 693-697

497 Morgan, M.J., Shelton, P.A. and Rideout, R.M. (2014) An evaluation of fishing mortality

498 reference points under varying levels of population productivity in three Atlantic cod (Gadus

499 morhua) stocks. ICES Journal of Marine Science 71,1407-1416

500 Pepin, P. (2015) Reconsidering the impossible - linking environmental drivers to growth,

501 mortality, and recruitment of fish 1. Canadian Journal of Fisheries and Aquatic Sciences 73, 205-

$502 \quad 215$

503 Pikitch, E., Santora, C., Babcock, E.A., Bakun, A., Bonfil, R., Conover, D.O., ... and Houde, 504 E.D. (2004) Ecosystem-based fishery management. Science 305, 346-347

505 Pitois, S.G. and Fox, C.J. (2006) Long-term changes in zooplankton biomass concentration and 506 mean size over the Northwest European shelf inferred from Continuous Plankton Recorder data. 507 ICES Journal of Marine Science 63, 785-798

508 Punt, A.E., A'mar, T., Bond, N.A., Butterworth, D.S., de Moor, C.L., De Oliveira, J.A., ... and 509 Szuwalski, C. (2013) Fisheries management under climate and environmental uncertainty:

510 control rules and performance simulation. ICES Journal of Marine Science 71, 2208-2220

511 Pyper, B.J. and Peterman, R.M. (1999) Relationship among adult body length, abundance, and 512 ocean temperature for British Columbia and Alaska sockeye salmon (Oncorhynchus nerka), 513 1967-1997. Canadian Journal of Fisheries and Aquatic Sciences, 56, 1716-1720 
514 Raab, K., Nagelkerke, L.A.J., Boerée, C., Rijnsdorp, A.D., Temming, A. and Dickey-Collas, M.

515 (2012) Dietary overlap between the potential competitors herring, sprat and anchovy in the North

516 Sea. Marine Ecology Progress Series 470, 101-111

517 Reid, P.C., de Fatima Borges, M., and Svendsen, E. (2001). A regime shift in the North Sea circa

5181988 linked to changes in the North Sea horse mackerel fishery. Fisheries Research 50(1), 163 -

$519 \quad 171$

520 Reid, P.C., Colebrook, J.M., Matthews, J.B.L., Aiken, J. C.P.R., and Team, C.P.R. (2003) The

521 Continuous Plankton Recorder: concepts and history, from plankton indicator to undulating

522 recorders. Progress in Oceanography 58, 117-173

523 Richardson, A. J., Walne, A. W., John, A. W. G., Jonas, T. D., Lindley, J. A., Sims, D. W., ...

524 and Witt, M. (2006) Using continuous plankton recorder data. Progress in Oceanography 68, 27$525 \quad 74$

526 Rindorf, A. and Lewy, P. (2001) Analyses of length and age distributions using continuation-

527 ratio logits. Canadian Journal of Fisheries and Aquatic Sciences 58, 1141-1152

528 Rindorf, A., Jensen, H. and Schrum, C. (2008) Growth, temperature, and density relationships of

529 North Sea cod (Gadus morhua). Canadian Journal of Fisheries and Aquatic Sciences 65, 456-470

530 Scheffer, M., Carpenter, S., Foley, J. A., Folke, C., and Walker, B. (2001). Catastrophic shifts in

531 ecosystems. Nature 413(6856), 591

532 Shephard, S., Rindorf, A., Dickey-Collas, M., Hintzen, N.T., Farnsworth, K. and Reid, D.G.

533 (2014) Assessing the state of pelagic fish communities within an ecosystem approach and the

534 European Marine Strategy Framework Directive. ICES Journal of Marine Science 71, 1572-1585 
535 Smith, M.D. and Jarre, A. (2011) Modelling regime shifts in the southern Benguela: a frame-

536 based approach. African Journal of Marine Science 33, 17-35

537 Stevens D. and Johns D. (2017) Monthly mean data for Calanus finmarchicus from CPR

538 standard. areas c1,c2,d1,d2 from 1958 -2015. Sir Alistar Hardy Foundation of Ocean science

539 (SAHFOS). Plymouth. DOI:10.7487/2017.17.1.1026. http://doi.sahfos.ac.uk/doi-

540 library/monthly-mean-data-for-calanus-finmarchicus-from-cpr-standard-areas-c1,c2,d1,d2-from-

$541 \quad 1958-2015 . a s p x$

542 Szuwalski, C.S., Vert-Pre, K.A., Punt, A.E., Branch, T.A., and Hilborn, R. (2015) Examining

543 common assumptions about recruitment: a meta-analysis of recruitment dynamics for worldwide

544 marine fisheries. Fish and Fisheries 16, 633-648

545 Tilman, D., Lehman, C.L. and Bristow, C.E. (1998) Diversity-stability relationships: statistical

546 inevitability or ecological consequence?. The American Naturalist 151, 277-282

547 van Deurs, M., van Hal, R., Tomczak, M.T., Jónasdottir, S.H. and Dolmer, P. (2009)

548 Recruitment of Lesser sandeel Ammodytes marinus in relation to density dependence and

549 zooplankton composition. Marine Ecology Progress Series 381, 249-258

550 van Deurs, M., Christensen, A. and Rindorf, A. (2013a) Patchy zooplankton grazing and high

551 energy conversion efficiency - Ecological implications of sandeel behavior and strategy. Marine

552 Ecology Progress Series 487, 123-133

553 van Deurs, M., Koski, M. and Rindorf, A. (2013b) Size composition of copepods determine

554 consumption of a particulate feeding planktivorous fish. ICES journal of Marine Science 71, 35-

$555 \quad 43$ 
556 van Deurs, M.V., Jørgensen, C. and Fiksen, Ø. (2015) Effects of copepod size on fish growth-a 557 model based on data for North Sea sandeel. Marine Ecology Progress Series 520, 235-243

558 Ware, D.M. and Thomson, R.E. (2005) Bottom-up ecosystem trophic dynamics determine fish 559 production in the Northeast Pacific. Science 308, 1280-1284 
560 Supporting information

561 Additional Supporting Information may be found online in the supporting information tab for this article.

562

563 
2 Table 1. Time trends. Pearson's product moment coefficients and p-values (in parenthesis) are 3 provided for the correlations of time versus recruitment success and length analomies,

4 respectively. Tests was made for both annual values and 3-year averages (see material and 5 methods). Significant correlations are in bold font.

\begin{tabular}{|c|c|c|c|}
\hline Stock & & Recruitment success & Length anomaly \\
\hline \multirow[t]{3}{*}{ Herring } & Trend in annual values & $-0.21(0.092)$ & $-0.45(0.001)$ \\
\hline & Trend in 3-year running mean & $-0.75(0.009)$ & $-0.53(0.079)$ \\
\hline & $\mathrm{n}$ & 67 & 49 \\
\hline \multirow[t]{3}{*}{ Norway pout } & Trend in annual values & $-0.14(0.4616)$ & $-0.51(<0.001)$ \\
\hline & Trend in 3-year running mean & $-0.47(0.0616)$ & $-0.62(0.014)$ \\
\hline & $\mathrm{n}$ & 30 & 41 \\
\hline \multirow[t]{3}{*}{ Southern sandeel } & Trend in annual values & $0.02(0.894)$ & $-0.41(0.013)$ \\
\hline & Trend in 3-year running mean & $0.10(0.688)$ & $-0.42(0.202)$ \\
\hline & $\mathrm{n}$ & 31 & 37 \\
\hline \multirow[t]{3}{*}{ Northern sandeel } & Trend & $-0.20(0.282)$ & $-0.34(0.037)$ \\
\hline & Trend in 3-year running mean & $-0.52(0.037)$ & $-0.31(0.179)$ \\
\hline & $\mathrm{n}$ & 31 & 37 \\
\hline \multirow[t]{3}{*}{ Sprat } & Trend in annual values & $-0.12(0.468)$ & $-0.30(0.060)$ \\
\hline & Trend in 3-year running mean & $-0.41(0.161)$ & $-0.34(0.255)$ \\
\hline & $\mathrm{n}$ & 40 & 41 \\
\hline
\end{tabular}

6 
10 Table 2. Principal component contributions of different stocks. Contribution indicates the 11 correlation between the species specific metric and the principal component. Large contributions 12 are present where the principal componenet closely follows the species specific metric, small 13 contributions indicate that the principal component does not reflect variation in the species 14 specific metric.

\begin{tabular}{llcc}
\hline Productivity metric & Stock & PC 1 contribution & PC 2 contribution \\
\hline Recruitment success & Herring & 0.44 & -0.20 \\
& Norway pout & 0.55 & 0.07 \\
& Sandeel (southern) & 0.11 & 0.73 \\
& Sandeel (northern) & 0.61 & 0.29 \\
Length anomaly before 1993 & Sprat & 0.35 & -0.59 \\
& Herring & -0.48 & -0.12 \\
& Norway pout & -0.40 & 0.73 \\
& Sandeel (southern) & 0.49 & -0.19 \\
& Sandeel (northern) & 0.40 & 0.62 \\
Length anomaly after 1993 & Sprat & 0.46 & 0.18 \\
& Herring & 0.56 & 0.36 \\
& Norway pout & 0.21 & 0.51 \\
& Sandeel (southern) & 0.46 & 0.31 \\
& Sandeel (northern) & -0.51 & 0.39 \\
& Sprat & -0.42 & 0.60 \\
\hline
\end{tabular}

15

16

17

18 
19 Table 3. Relative change in weight at age, recruitment, MSY, and $F_{\text {msy }}$ for each stock. Values are 20 given as \% change between the period before 1993 and the period after 1993 (minus indicate a 21 negative change). Data on mean weight at age and recruitment were adopted from the stock 22 assessment reported by ICES and are the same data applied in the calculations of MSY and $\mathrm{F}_{\mathrm{ms}} \mathrm{y}$ 23 (see material and methods).

\begin{tabular}{lcccc}
\hline Stock & Weight at age & Recruitment & MSY & Fmsy \\
\hline Sandeel (southern) & $-26 \%$ & $-23 \%$ & $-56 \%$ & $-50 \%$ \\
Sandeel (northern) & $-24 \%$ & $-52 \%$ & $-68 \%$ & $-64 \%$ \\
Sprat & $-6 \%$ & $-9 \%$ & $-34 \%$ & $-48 \%$ \\
Herring & $-3 \%$ & $-27 \%$ & $-33 \%$ & $-26 \%$ \\
Norway pout & $-8 \%$ & $-29 \%$ & $-45 \%$ & $-41 \%$ \\
\hline
\end{tabular}

24

25

26

27 
2 Fig. 1. Development in length analomy (solid line) of herring (a), sprat (b), Norway pout (c), 3 southern sandeel (d), northern sandeel (e) and all stocks together (f). Broken lines show averages 4 before and after 1993.

7 Fig. 2. Development in recruitment success (solid line) of herring (a), sprat (b), Norway pout (c), 8 southern sandeel (d), northern sandeel (e) and all stocks together (f). Broken lines show averages 9 before and after 1993.

12 Fig. 3. Correlations between Calanus finmarchicus and the first principal component of 13 recruitment (a) and growth (b,c). Since the PCA analysis of growth was divided into an early 14 period and a late period (see Material and Methods), the correlation analyses were also didvided 15 in two (b,c). All correlations were significant according to Pearson's product-moment correlation 16 test (see Results).

Fig. 4. Model simulations of how the combined forage fish spawning stock biomass would have developed even without fishing $(\mathrm{F}=0)$ (i.e. the potential forage fish biomass). Black line is the mean of one thousand simulations and grey lines represents the standard deviations. Hence, the

22 decline is caused by the introduction of the observed changes in stock recruitment and weight at 23 age in the stocks into the model (see table 4). The grey field defines the trasition zone between 24 the high productivity period and the low productivity period. 

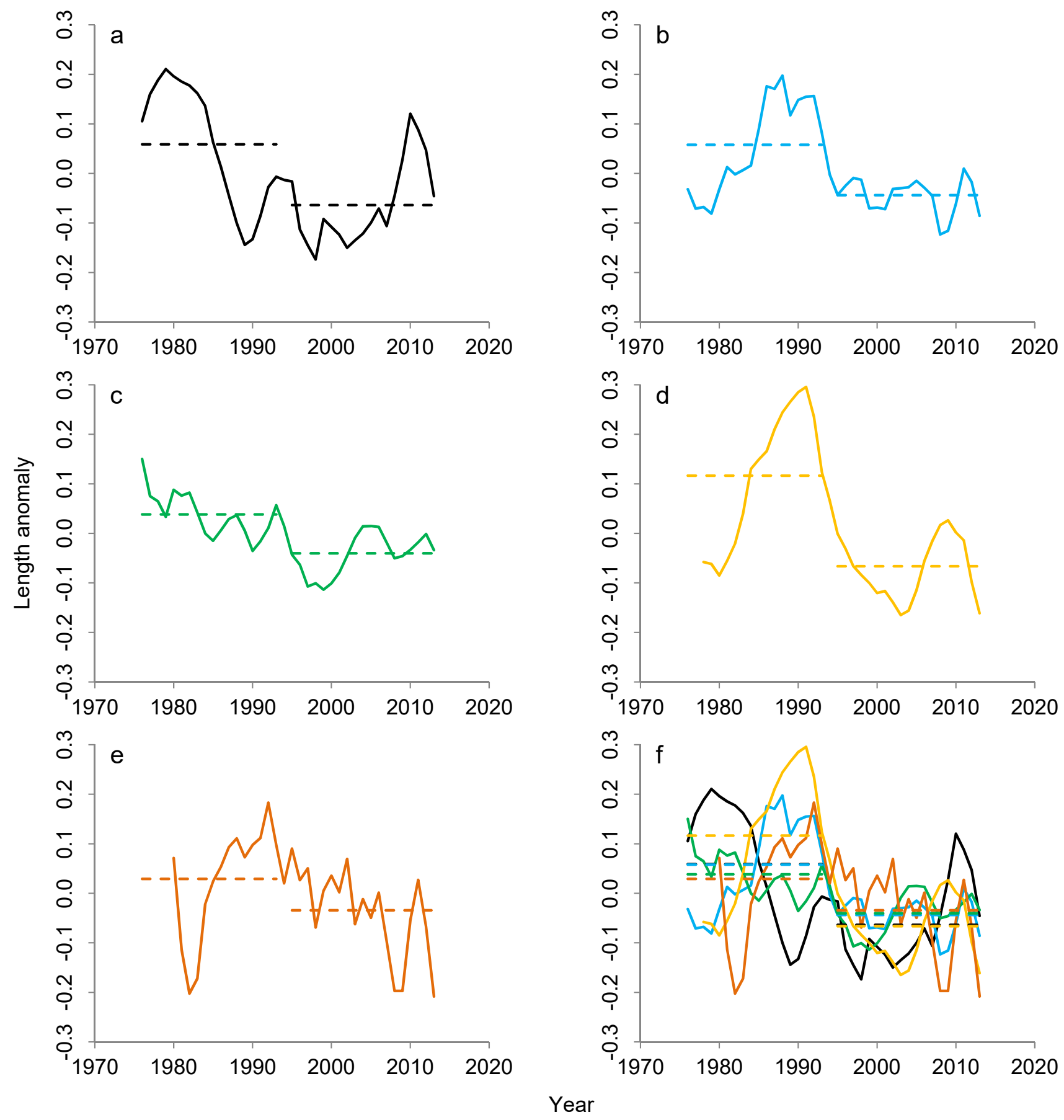

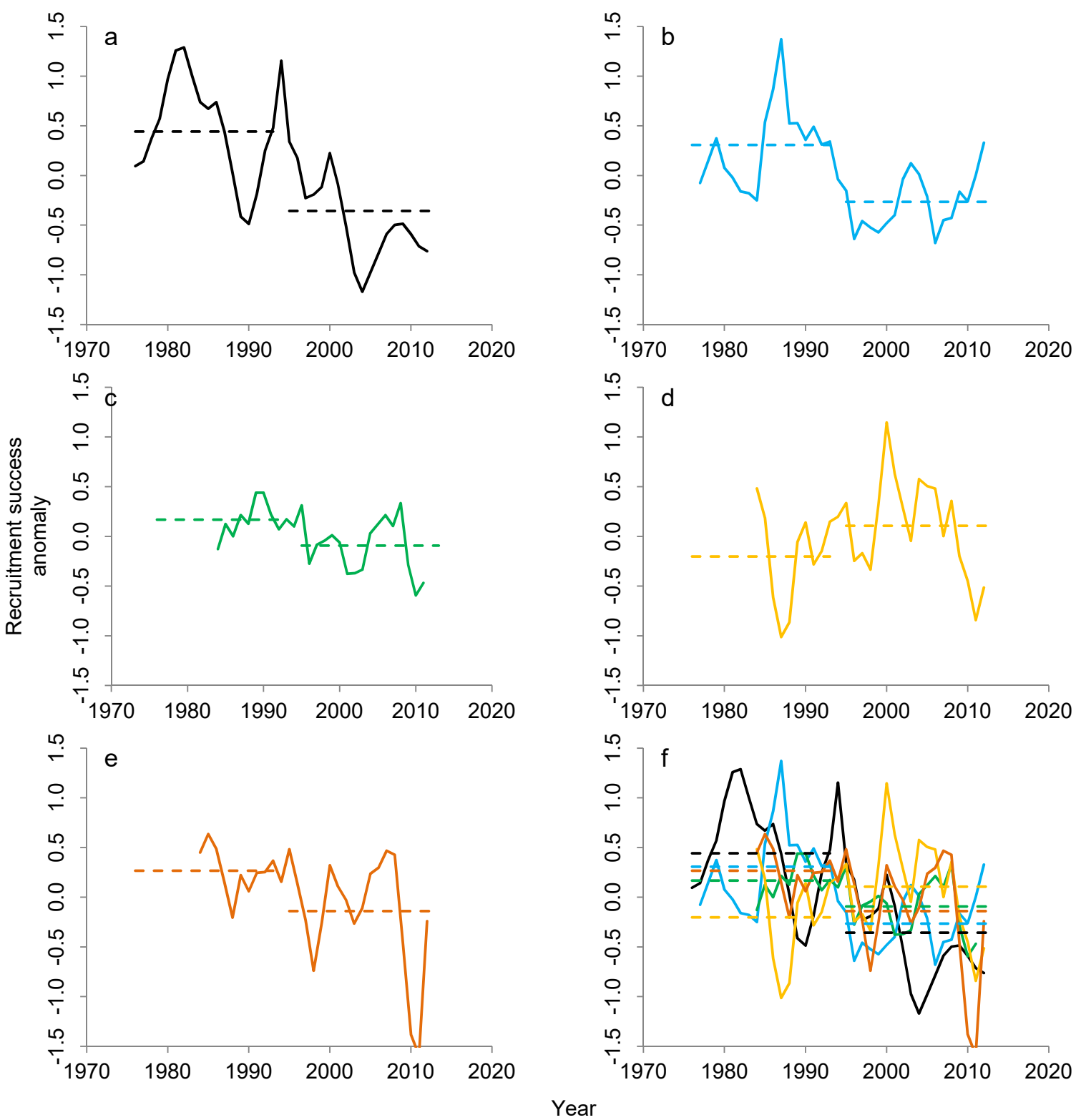


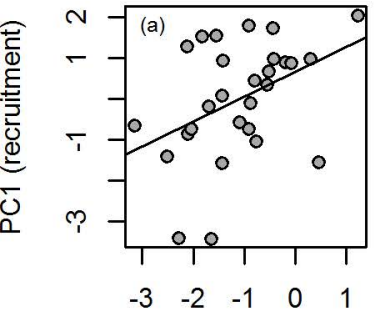

Calanus finmarchicus index

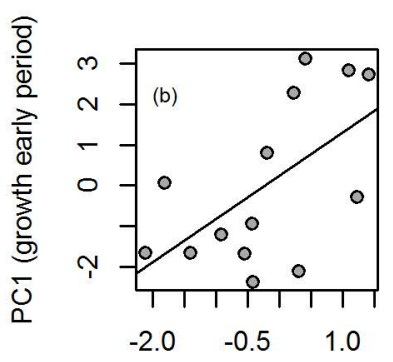

Calanus finmarchicus index

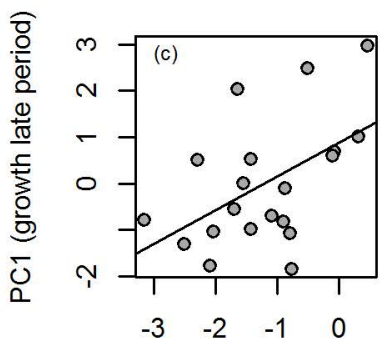

Calanus finmarchicus index 


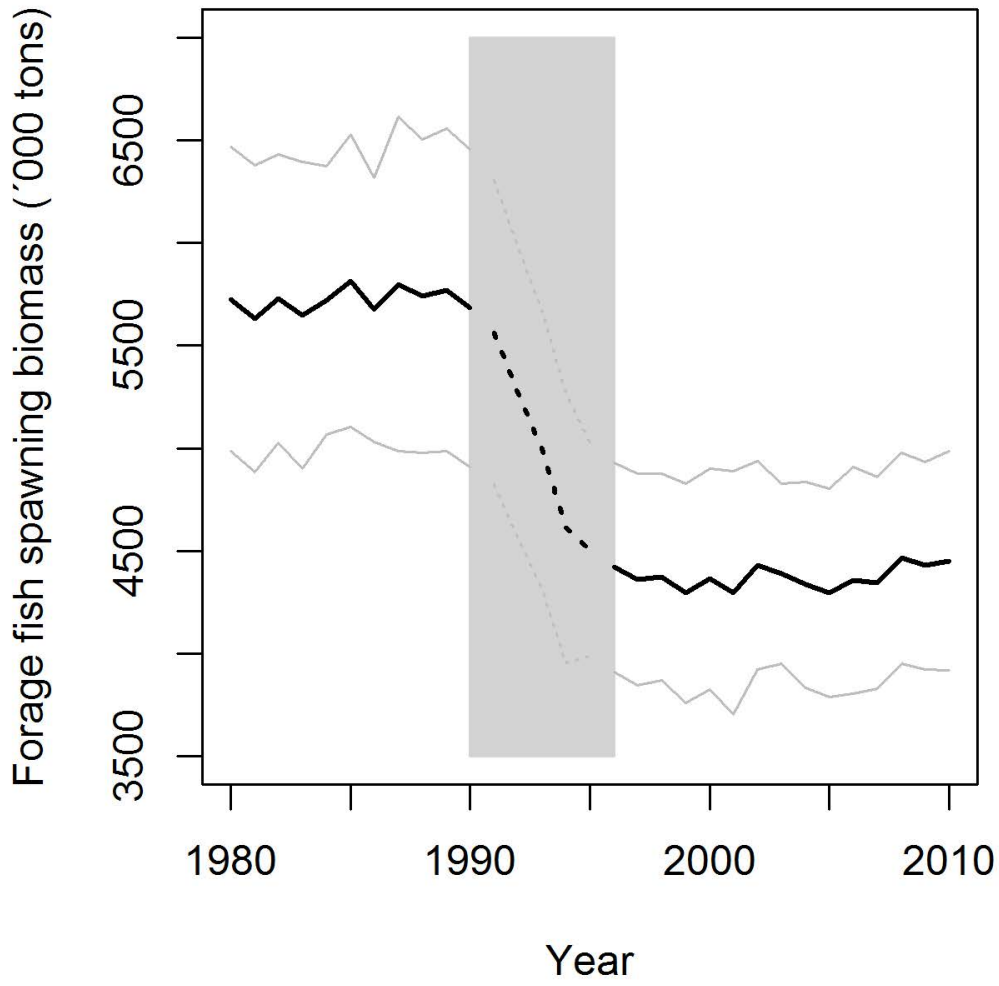




\section{Estimation of MSY and $\mathbf{F}_{\text {MSY }}$}

5 The model tracks cohort development influenced by an age- and season-specific natural

6 mortality $(M)$ and fishing mortality $(F)$ (according to the resolution applied in the corresponding

7 ICES stock assessments). Stock numbers $(N)$ are derived for discrete age groups $\left(a_{i} \in\left[a_{0}, a_{1} \ldots\right.\right.$

$\left.\left.8 a_{\max }\right]\right)$ and updated at the beginning of each time step $\left(t_{\mathrm{i}} \in\left[\mathrm{t}_{1}, \mathrm{t}_{2}, \ldots \mathrm{t}_{\max }\right]\right.$ (i.e. $\mathrm{t}_{\max }$ equals 4 if the

9 stock is analyzed in quarterly time steps) in each year $\left(\mathrm{y}_{\mathrm{i}}\right)$ :

10

11

12 The youngest age group is age- $0\left(a_{0}\right) \cdot a_{0}$ in $\mathrm{t}_{1}$ signifies the recruitment $(R)$ of young fish to the 13

.

$$
\text { stock and is modelled as a function of spawning stock biomass }(S) . a_{\max } \text { is a plus-group and }
$$
covers all age groups at or above the oldest age group for which accurate data is available. $N$ is the stock number for any given age group $\left(a_{i}\right)$, season $\left(t_{i}\right)$, and simulation year $\left(y_{i}\right)$. Each simulation year starts at the time of spawning, in accordance with the biology of these stocks. $\mathrm{N}_{\text {initiate }}$ is the initial stock numbers required to initiate the simulations. $f(S)$ is the stockrecruitment function, in this case a hockey-stick function (with the horizontal bar equal to the geometric mean recruitment for the specific stock and period (as previously described) and the brake point equal to $\mathrm{B}_{\mathrm{lim}}$ ), to which a log-normal distributed error term is added to simulate environmental variation ( $\sigma_{\mathrm{R}}=0.35$ was applied for all stocks). $S$ at the onset of $\mathrm{y}_{\mathrm{i}}$ is calculated from stock numbers at age, the mean weight, and proportion mature. Proportion mature were the same independent of the period and corresponded to the values applied by ICES in the current short-term projections (see ICES 2015a,b). F in the model is composed of a multiplier and a

$$
N_{a_{i}, t_{i}, y_{i}}=\left\{\begin{array}{l}
N_{\text {initiate }}, t_{i}=t_{1} \wedge y_{i}=y_{1} \\
f\left(S_{y_{i}}\right) \times e^{\sigma_{R} \times \operatorname{NORM}(0,1)}, t_{i}=t_{1} \wedge a_{i}=a_{0} \wedge y_{i}>y_{1} \\
N_{a_{a_{-1},}, t_{\max }, y_{i-1}} \times e^{-M_{a_{i}, t_{i}}-F_{a_{i}, t_{i}}}, t_{i}=t_{1} \wedge a_{i}>a_{0} \wedge y_{i}>y_{1} \\
N_{a_{i}, t_{i-1}, y_{i}} \times e^{-M_{a_{i}, t_{i}}-F_{a_{i}, t_{i}}}, t_{i}>t_{1} \wedge a_{i}>a_{0} \wedge y_{i}>y_{1}
\end{array}\right.
$$


constant age- and season-specific exploitation pattern. $\mathrm{B}_{\lim }, M$, proportion mature, and the exploitation pattern were the same independent of the period and were adopted from ICES (2015a,b). F and $M$ was implemented in the population using Pope's approximation (Myers and Cadigan 1995), which was applied with ten sequential iteration cycles for each season and age group. The associated catch in tons was derived by summing up the numbers removed by $F$ in each sequential iteration cycle and from each age group and season multiplied by the age- and season-specific mean weights. The 'perceived' stock is modelled at the beginning of the simulation year $\left(t_{1}\right)$ as the true value plus an error term to mimic uncertainty in stock number estimates. The following equation is used to generate the 'perceived' stock numbers:

$$
N_{a_{1} \ldots a_{\max }, t_{1}, y_{i}}^{\prime}=\operatorname{NORM}\left(N_{a_{1} \ldots a_{\max }, t_{1}, y_{i}}, \sigma_{N}\right)
$$

where $\sigma_{N}$ is the virtual "stock assessment uncertainty" of stock number estimates $\left(\sigma_{N}=0.3\right.$ was applied for all stocks and both periods).

The shifts in $\mathrm{F}_{\mathrm{msy}}$ reported in the Table 3 in the main text is driven solely by shifts in mean weight at age and recruitment (i.e. the upper level of the $S$ - $R$ hockey stick), which can be derived from data reported in ICES (2015a,b). As an example of data input, Table S1 provides the the upper level of the $S$ - $R$ hockey stick from before and after 1993, calculated as the geometric mean recruitment in years where $S$ was above $\mathrm{B}_{\lim }$, and fig. $S 1$ depicts the $S$ - $R$ scatter plots adopted from the respective ICES assessment working group reports ICES (2015a,b).

$\mathrm{F}_{\text {msy }}$ (i.e. the $F$ that leads to a probability $P$ of 0.05 of falling below $B_{\text {lim }}$ ) was identified by calculating $P\left(S<\mathrm{B}_{\text {lim }}\right)$ for a range of different $F$ values and for each stock and period, respectively (fig. S2).

Model assumptions were kept at a minimum to homogenize the individual sub models, such that the results reported in table 3 in the main text arrived only from the stock specific differences in weight at age and recruitment, before and after 1993. 


\section{Analyses of time trend and common patterns in recruitment residuals from a Ricker relationship

The methods used here are identical to the analysis given in the main manuscript with the exception that the recruitment indicator used was the annual residual from a Ricker relationship

57 between spawning stock biomass $(S)$ and recruitment $(R)$ (Ricker 1954), rather than $\ln (R / S)$. The

58 fitted stock recruitment relationships are shown in fig. S3. The temporal development in the 59 residuals can be seen in fig. S4.

60 All stocks displayed decreasing trends in recruitment anomalies similarly to the analyses

61 conducted using $\ln (R / S)$ in the main text (Table S2), and also when using 3-year running 62 averages (Table S2).

63 PC1 for recruitment success explained $42 \%$ of the total variation and PC2 added another $28 \%$.

64 Similarly to the analyses conducted with $\ln (R / S)$, PC1 was positively correlated to the 65 recruitment success of all stocks, although the correlation with southern sandeel was weak (Table 66 S3).

67 PC2 was positively correlated to southern sandeel and negatively correlated to sprat, indicating 68 that years of high recruitment success for one of these stocks matched up with years of poor recruitment success for the other. PC1 showed a significant decreasing trend over time

70 (Pearson's product moment correlation: correlation $-0.76, \mathrm{p}<0.0001$ ), indicating a general

71 decrease in forage fish recruitment success.

72 Detailed information about correlations between individual stocks can be found in Table S4. This 73 information were not included in the main document. 
80 ICES (2015a) Report of the Working Group for the Assessment of Demersal Stocks in the North

81 Sea and Skagerrak (WGNSSK). ICES CM 2015/ACOM:13

82 ICES (2015b) Report of the Herring Assessment Working Group for the Area South of $62^{\circ} \mathrm{N}$

83 (HAWG). ICES CM 2015/ACOM:03

84 Myers, R.A. and Cadigan, N.G. (1995) Was an increase in natural mortality responsible for the

85 collapse off northern cod? Canadian Journal of Fisheries and Aquatic Sciences 52, 1274-1285

86 Ricker, W.E. (1954) Stock and recruitment. Journal of the Fisheries Board of Canada, 11(5),

$87 \quad 559-623$

88

89

90 Table S1. Upper levels of the $S-R$ hockey sticks before and after 1993. Only recruitment values

91 from years where spawning stock size was above $B_{\lim }$ was included in the geometric means.

92 Numbers are calculated from data $\left(\mathrm{B}_{\text {lim }}, S\right.$, and $R$ ) reported in ICES (2015a,b).

\begin{tabular}{llc}
\hline Stock & Period & Geom. mean recruitment $\left(10^{9}\right)$ \\
\hline Herring & after & 367 \\
& before & 515 \\
Norway Pout & after & 39 \\
& before & 55 \\
Sandeel (North) & after & 89 \\
& before & 186 \\
Sandeel (South) & after & 179 \\
& before & 232 \\
Sprat & after & 145 \\
& before & 160 \\
\hline
\end{tabular}

93 
94 Table S2. Time trends. Pearson's product moment coefficients and p-values (in parenthesis) are 95 provided for the correlations of time versus recruitment anomalies. Tests were made for both 96 annual values and 3-year averages (see material and methods). Significant correlations are in 97 bold font.

\begin{tabular}{|c|c|c|}
\hline Stock & & Recruitment success \\
\hline \multirow[t]{3}{*}{ Herring } & Trend in annual values & $-0.49(0.0012)$ \\
\hline & Trend in 3-year running mean & $-0.60(<0.0001)$ \\
\hline & $\mathrm{n}$ & 40 \\
\hline \multirow[t]{3}{*}{ Norway pout } & Trend in annual values & $-0.13(0.5019)$ \\
\hline & Trend in 3-year running mean & $-0.42(0.0244)$ \\
\hline & $\mathrm{n}$ & 30 \\
\hline \multirow[t]{3}{*}{ Southern sandeel } & Trend in annual values & $-0.26(0.1632)$ \\
\hline & Trend in 3-year running mean & $-0.46(0.0114)$ \\
\hline & $\mathrm{n}$ & 31 \\
\hline \multirow[t]{3}{*}{ Northern sandeel } & Trend in annual values & $-0.24(0.1949)$ \\
\hline & Trend in 3-year running mean & $-0.55(0.0019)$ \\
\hline & $\mathrm{n}$ & 31 \\
\hline \multirow[t]{3}{*}{ Sprat } & Trend in annual values & $-0.33(0.0384)$ \\
\hline & Trend in 3-year running mean & $-0.52(0.0007)$ \\
\hline & $\mathrm{n}$ & 40 \\
\hline
\end{tabular}

98

99

100

101

102 
103 Table S3. Principal component contributions of different stocks. Contribution indicates the 104 correlation between the species specific metric and the principal component. Large contributions 105 are present where the principal component closely follows the species specific metric, small 106 contributions indicate that the principal component does not reflect variation in the species 107 specific metric.

\begin{tabular}{lllc}
\hline Productivity metric & Stock & PC 1 contribution & PC 2 contribution \\
\hline Recruitment success & Herring & 0.55 & -0.11 \\
& Norway pout & 0.32 & -0.53 \\
& Sandeel (southern) & 0.53 & 0.08 \\
& Sandeel (northern) & 0.54 & 0.69 \\
\hline
\end{tabular}

108

109

110

111

112

113

114

115

116

117

118 
119 Table S4. Correlations between stock. Pearson's product moment coefficients and p-values (in 120 parenthesis) are provided for all combinations of stocks and for recruitment success and length 121 analomies, respectively. Significant correlations are in bold font.

\begin{tabular}{|c|c|c|c|c|c|}
\hline Productivity metric & Stock & Norway pout & Sandeel (southern) & Sandeel (northern) & S \\
\hline \multirow[t]{4}{*}{ Recruitment success (3 year averages) } & Herring & $-0.01(0.973)$ & $0.00(0.993)$ & $0.30(0.106)$ & 0.09 \\
\hline & Norway pout & & $0.39(0.034)$ & $0.49(0.006)$ & 0.39 \\
\hline & Sandeel (southern) & & & $0.54(0.002)$ & -0.13 \\
\hline & Sandeel (northern) & & & & 0.22 \\
\hline \multirow[t]{4}{*}{ Length anomaly before 1993} & Herring & $0.35(0.136)$ & $-0.77(<0.001)$ & $-0.10(0.701)$ & -0.67 \\
\hline & Norway pout & & $-0.56(0.020)$ & $0.02(0.932)$ & -0.22 \\
\hline & Sandeel (southern) & & & $0.27(0.318)$ & 0.64 \\
\hline & Sandeel (northern) & & & & -0.01 \\
\hline \multirow[t]{4}{*}{ Length anomaly after 1993} & Herring & $-0.25(0.270)$ & $0.33(0.151)$ & $0.04(0.855)$ & -0.19 \\
\hline & Norway pout & & $-0.05(0.830)$ & $-0.21(0.378)$ & 0.12 \\
\hline & Sandeel (southern) & & & $0.09(0.715)$ & -0.04 \\
\hline & Sandeel (northern) & & & & 0.52 \\
\hline
\end{tabular}

122

123

124

125 

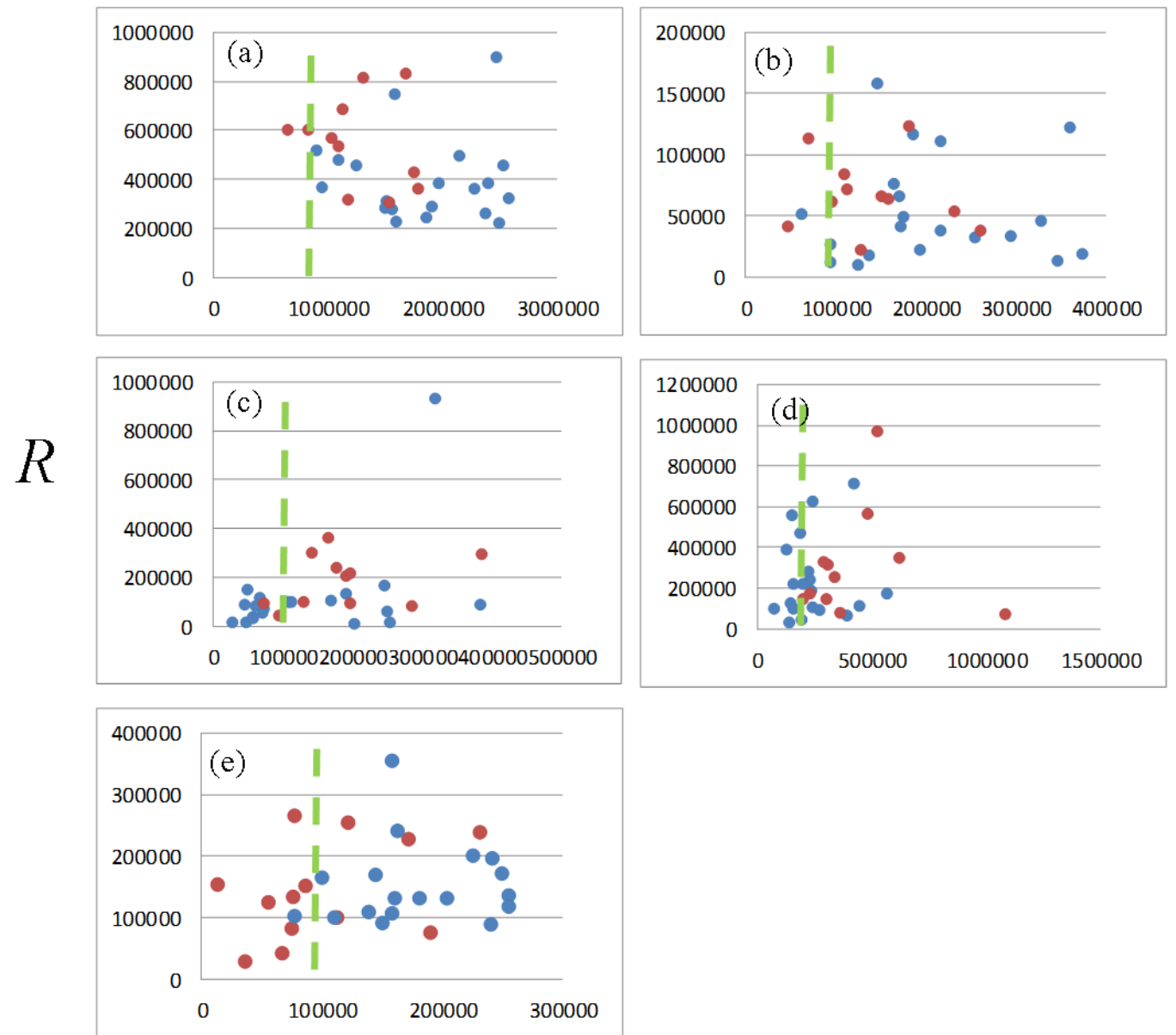

127 Figure S1. Scatter plots of spawning stock biomass ( $S$ [tons]) versus recruitment ( $R$ [millions])

128 for each stock, respectively; Herring (a), Norway Pout (b), Northern sandeel (c), Southern 129 sandeel (d), and sprat (e). Before 1993 (red) and after 1993 (blue). $\mathrm{B}_{\text {lim }}$ is represented by a 130 vertical green dashed line. Data was taken from the respective ICES assessment working group 131 reports ICES (2015a,b) 

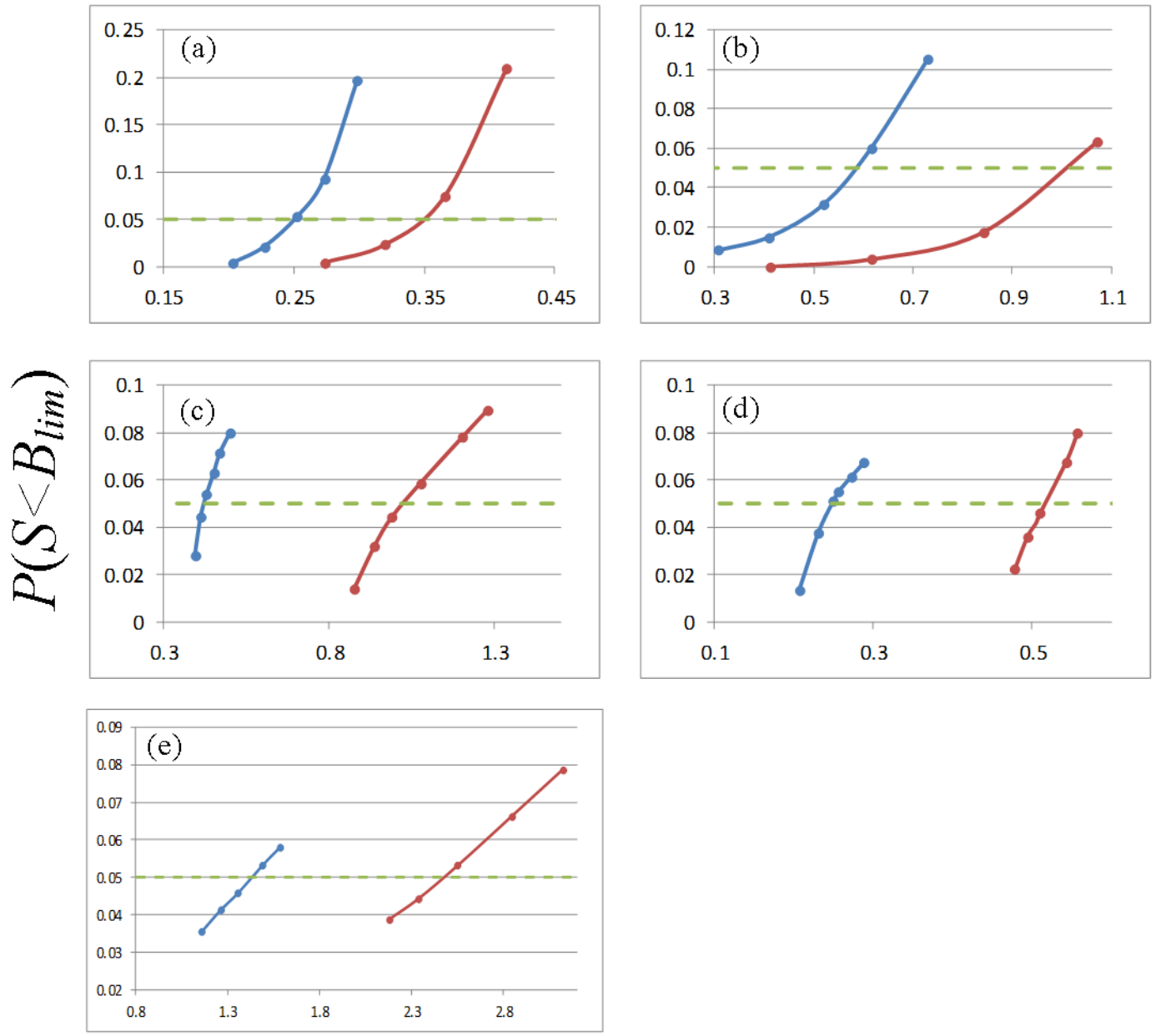

133

F

134 Figure S2. The probability $P$ of falling below $B_{\text {lim }}$ calculated for a range of $F$ values and for each 135 stock and period, respectively; Herring (a), Norway Pout (b), Northern sandeel (c), Southern 136 sandeel (d), and sprat (e). Before 1993 (red curve) and after 1993 (blue curve). Green dashed line 137 defines $P\left(S<\mathrm{B}_{\text {lim }}\right)=0.05$ and $\mathrm{F}_{\text {msy }}$ is where the green dashed line intercepts with the curves. 
Herring

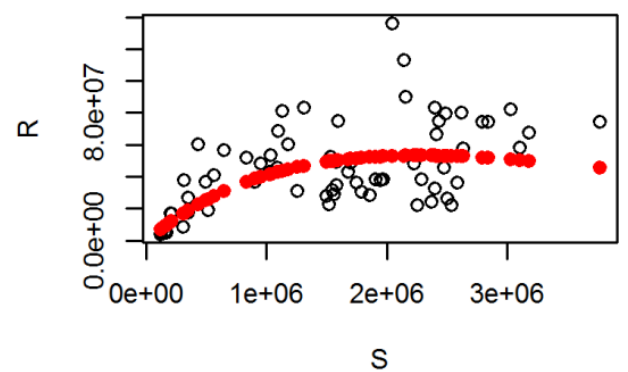

Sandeel(south)

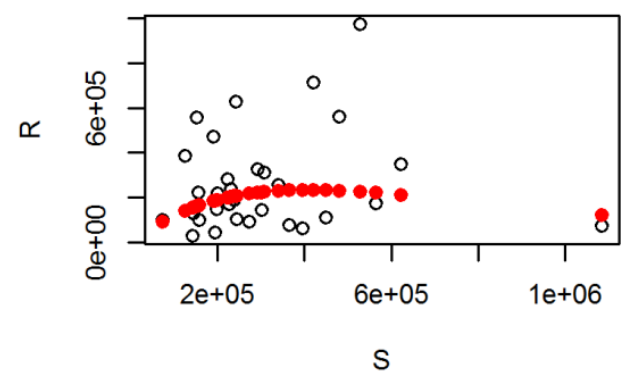

Sprat

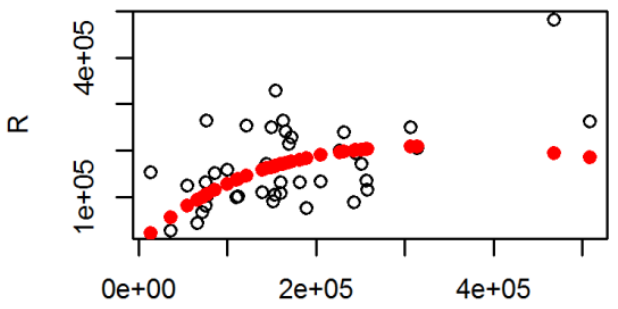

Norway pout

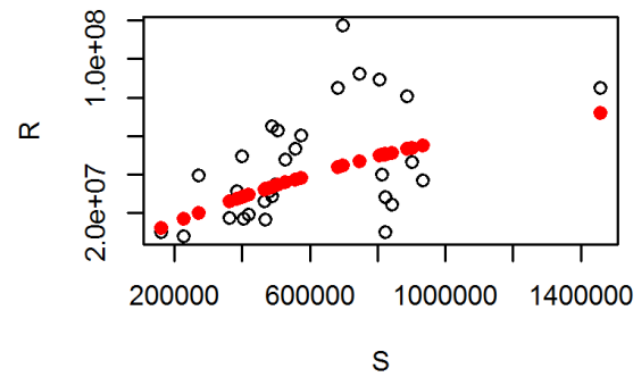

Sandeel(north)

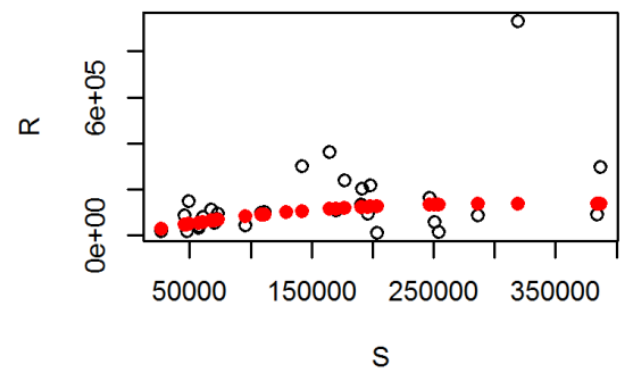

143 Figure S3. Scatter plots of spawning stock biomass $(S)$ and recruitment $(R)$ for each stock. Red 144 points represent fitted values using a Ricker stock-recruitment model (Ricker 1954). 
Herring

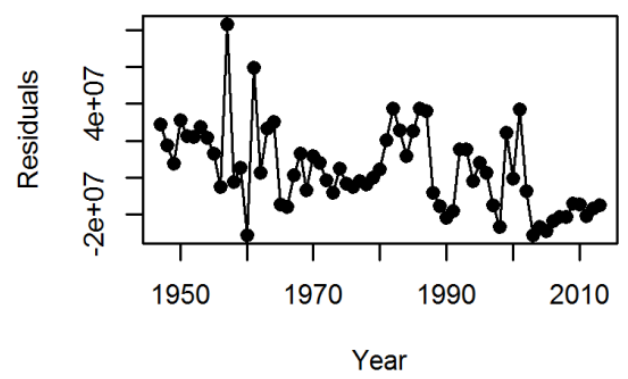

Sandeel(south)
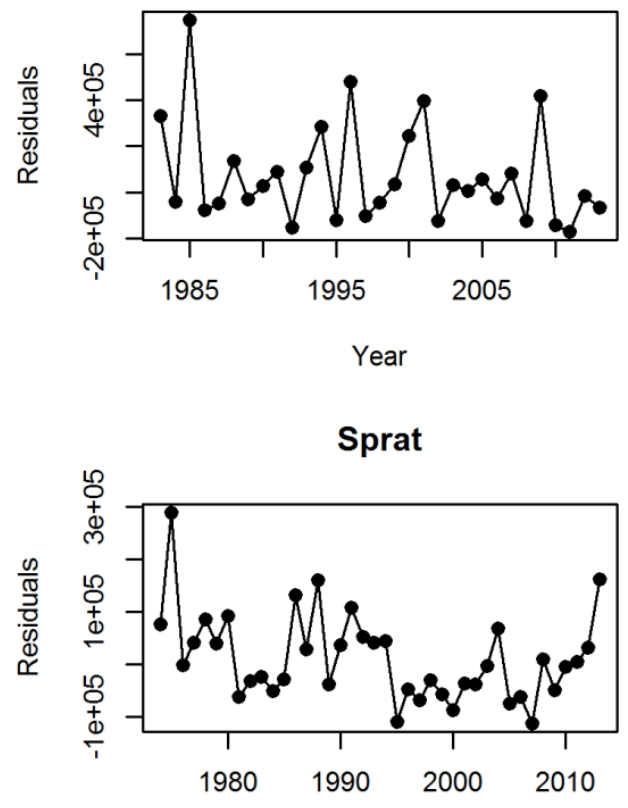

146

147 148 149 150
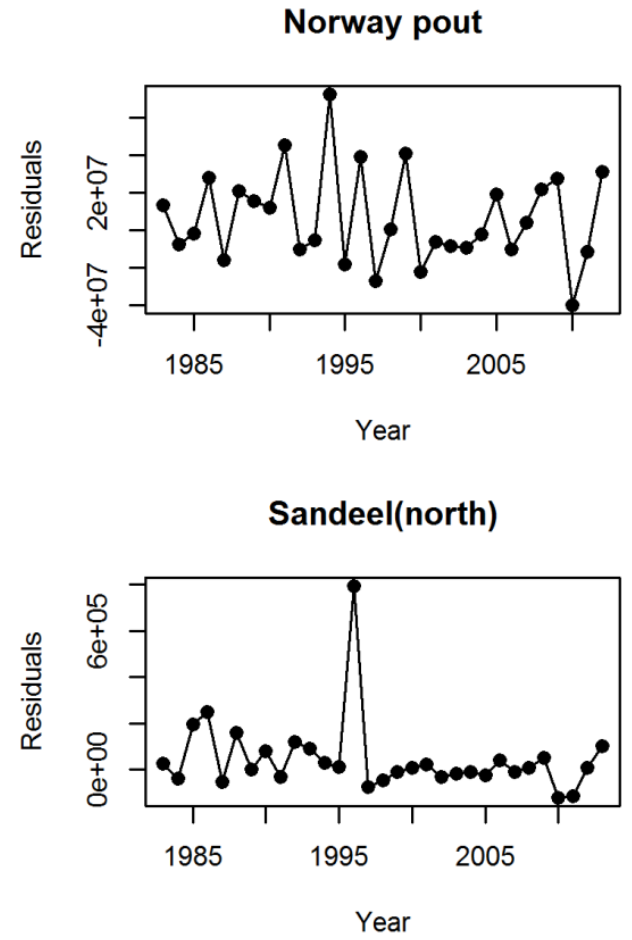